\title{
Infecciones comunitarias que requieren ingreso en $\mathrm{UCI}$
}

\author{
J. Blanquer ${ }^{\mathrm{a}, *}$, J. Solé-Violán ${ }^{\mathrm{b}}$, J. Carvajal $^{\mathrm{c}}$ y F. Lucena ${ }^{\mathrm{d}}$ \\ ${ }^{a} U C I$, Hospital Clinic Universitari, Valencia, España \\ bServicio de Medicina Intensiva, Hospital Dr. Negrín, Las Palmas de Gran Canaria, España \\ 'Servicio de Medicina Intensiva, Hospital de Santa Bárbara, Puertollano, Ciudad Real, España \\ ${ }^{\mathrm{d} S e r v i c i o ~ d e ~ M e d i c i n a ~ I n t e n s i v a, ~ H o s p i t a l ~ U n i v e r s i t a r i o ~ d e ~ V a l m e, ~ S e v i l l a, ~ E s p a n ̃ a ~}$
}

Recibido el 12 de marzo de 2010; aceptado el 12 de marzo de 2010

\author{
PALABRAS CLAVE \\ Neumonías \\ comunitarias graves; \\ Meningitis; \\ Encefalitis; \\ Infecciones del tracto \\ urinario; \\ Reacción en cadena \\ de polimerasa; \\ Betalactamasas de \\ espectro extendido
}

\section{KEYWORDS}

Severe communityacquired pneumonias;

Meningitis;

Encephalitis;

Urinary tract

infections;

Polymerase chain

reaction;

Extended spectrum

betalactamases

\begin{abstract}
Resumen
Se analizan las características clínicas, diagnóstico y tratamiento de las infecciones comunitarias más graves y frecuentes en la UCl: neumonías comunitarias graves, meningitis, encefalitis e infecciones del tracto urinario. Con respecto a las neumonías se hace hincapié en la utilización de las escalas de gravedad para valorar el ingreso en las unidades de críticos, así como en la monitorización evolutiva mediante los marcadores biológicos y en la importancia de instaurar un tratamiento antibiótico precoz adecuado. Se resalta la importancia del Gram de líquido cefalorraquídeo en el diagnóstico etiológico de la meningitis, así como de las técnicas de amplificación por reacción en cadena de polimerasa a tiempo real y de la RM en el diagnóstico etiológico de las encefalitis. Asimismo, se expresa la preocupación por el aumento del porcentaje de cepas de Escherichia coli y Klebsielella pneumoniae productoras de betalactamasas de espectro extendido en nuestro país.

(c) 2010 Elsevier España, S.L. y SEMICYUC. Todos los derechos reservados.
\end{abstract}

\section{Community infections that require admission to the ICU}

\begin{abstract}
The clinical and diagnostic characteristics and treatment of the most severe and frequent community-acquired infections in the Intensive Care Units are analyzed. These are serious community-acquired pneumonias, meningitis, encephalitis and urinary tract infections. Regarding the pneumonias, emphasis is placed on the use of the severity scales to evaluate admission in the critical units, on evolutive monitoring using biological markers and on the importance of initiating adequate early antibiotic treatment. The importance of the Gram staining of the cerebral spinal fluid in the etiological diagnosis of meningitis, of the polymerase chain reaction amplification techniques in real time and of the magnetic resonance imaging in the etiological diagnosis of the encephalitis. Furthermore, concern is
\end{abstract}

\footnotetext{
*Autor para correspondencia.

Correo electrónico: blanquer_jos@gva.es (J. Blanquer).
} 
expressed regarding the increase of the percentage of the strains of extended spectrum betalactamase-producing Escherichia coli and Klebsiella pneumoniae in our country. (c) 2010 Elsevier España, S.L. and SEMICYUC. All rights reserved.

\section{Introducción}

Las infecciones comunitarias requieren con frecuencia su admisión en la Unidad de Medicina Intensiva (UMI), tanto por necesidades terapéuticas inherentes a la gravedad intrínseca del cuadro como por el requerimiento de una adecuada monitorización del proceso.

En esta puesta al día hemos desarrollado, para adaptarnos al espacio del que disponemos, dentro del extenso campo de infecciones comunitarias que pueden requerir su ingreso en la UMI, aquellas que, tanto por su gravedad como por su elevada frecuencia constituyen los problemas infecciosos más frecuentes en nuestro quehacer diario: neumonías, infecciones del SNC e infecciones del tracto urinario.

\section{Neumonía adquirida en la comunidad}

La incidencia de la neumonía adquirida en la comunidad (NAC) en adultos oscila entre $2-10$ casos/1.000 habitantes/ año, con tasas de hospitalización que fluctúan de $20-35 \%$, de los que 6-10\% ingresan en la UMI. Es la causa de muerte más frecuente de origen infeccioso, que puede alcanzar $24-40 \%$ en el subgrupo de pacientes ingresados en la $\mathrm{UMI}^{1,2}$.

En la mayoría de los estudios solo se puede demostrar la etiología de las NAC en cerca de la mitad de los casos. Los agentes etiológicos más frecuentes en las NAC graves son S. pneumoniae, Legionella pneumophila y Hemophilus influenzae, aunque las enterobacterias (sobre todo Klebsie(la pneumoniae) suelen provocar NAC en pacientes con comorbilidades o que recibieron antibioterapia previa, y Pseudomonas aeruginosa se identifica en 3-5\% de NAC, en relación con la presencia de bronquiectasias, fibrosis quística, EPOC grave, neoplasias y neutropenia ${ }^{2,3}$. Staphylococcus aureus se suelen presentar tras infecciones virales. Los virus, más frecuentes en las NAC infantiles, se suelen presentar en adultos como copatógenos asociados a neumococo, $H$ influenzae y estafilococo aureus, sobre todo Influenza A y B, virus sincitial respiratorio, parainfluenza 1,2 y $3^{4}$. Los microorganismo atípicos, como Mycoplasma pneumoniae y Chlamydophila pneumoniae, a menudo copatógenos, también pueden ocasionar cuadros graves.

Las recientes normativas elaboradas conjuntamente por la Sociedad Americana del Tórax (ATS) y la Sociedad Americana de Enfermedades Infecciosas (IDSA) proponen el ingreso directo en UMI a los pacientes con shock séptico o insuficiencia respiratoria aguda que precisen ventilación mecánica, así como a los pacientes que presenten al menos 3 de 9 criterios menores ${ }^{5}$ (tabla 1 ). Las escalas de gravedad más recientes, como el SMART-COP, han mostrado su utilidad para identificar los pacientes que requerirán asistencia respiratoria o hemodinámica ${ }^{6}$, o como el REA-UCI para pronosticar el requerimiento de $\mathrm{UCl}$ durante los primeros 3 días de hospitalización ${ }^{7}$. Los niveles altos de biomarcadores inflamatorios cuando acompañan a estos sistemas de puntuación pueden mejorarlos, mientras que su elevación persistente puede identificar de forma precoz la mala respuesta al tratamiento ${ }^{8}$.

Se ha desarrollado un índice para evaluar la gravedad de las NAC ingresadas en la UMI, basado en el sistema PIRO (acrónimo de Predisposición, Infección, Respuesta del huésped, y disfunción Orgánica), útil para identificar a los pacientes con mayor riesgo de muerte, que podrían beneficiarse de intervenciones terapéuticas dirigidas a modular la respuesta inflamatoria?.

La administración rápida y efectiva de antibióticos puede reducir la mortalidad de la NAC grave, por lo que debe ser prioritario su inicio precoz tras establecer el diagnóstico de neumonía y obtener muestras microbiológicas de calidad, sobre todo en pacientes con shock séptico, donde cada hora de retraso se asocia a mayor mortalidad. La evaluación inmediata de la saturación arterial de la $\mathrm{Hb}$ mediante pulsioximetría podría identificar rápidamente a los pacientes con hipoperfusión periférica o hipoxemia, que precisan una atención inmediata ${ }^{10}$.

El espectro del tratamiento antibiótico debe ser amplio, capaz de cubrir los agentes etiológicos más probables, valorando la gravedad del cuadro clínico, la posible existencia de factores de riesgo para infección por microorganismos específicos, los patrones epidemiológicos propios de cada área geográfica y su susceptibilidad antimicrobiana ${ }^{2}$.

La neumonía relacionada con el sistema sanitario, a nuestro entender, es un grupo con características propias que la diferencian de la NAC y de la neumonía nosocomial (tabla 2). No existe consenso sobre su tratamiento, pero probablemente debe individualizarse ${ }^{11}$.

Todos los pacientes con NAC grave deben recibir cobertura adecuada frente a Streptococcus pneumoniae y Legionella sp,

Tabla 1 Criterios de neumonía adquirida en la comunidad grave

Criterios mayores Necesidad de ventilación mecánica Presencia de shock séptico

Criterios menores Tensión arterial sistólica $<90 \mathrm{mmHg}$ Frecuencia respiratoria $\geq 30 \mathrm{rpm}$ $\mathrm{PaO} 2 / \mathrm{FiO} 2<250$ Infiltrados multilobares Confusión y/o desorientación Uremia (BUN $>20 \mathrm{mg} / \mathrm{dl}$ ) Hipotermia $<36{ }^{\circ} \mathrm{C}$ Leucopenia $<4 \times 10^{9}$ leucocitos/l Trombocitopenia $<100 \times 10^{9}$ plaquetas/ l

La presencia de 1 criterio mayor o 3 criterios menores define la neumonía grave.

BUN: nitrógeno ureico; $\mathrm{PaO}_{2} / \mathrm{FiO}_{2}$ : cociente entre presión de oxígeno arterial y fracción inspiratoria de oxígeno. 
Tabla 2 Neumonía relacionada con el sistema sanitario

Hospitalización ( $>2$ días) en los últimos 3 meses

Residencia en institución sociosanitaria

Hemodiálisis crónica

Tratamiento antibiótico, inmunosupresor o curas de heridas

en últimos 30 días

Miembro de familia con patógeno multiresistente

Tabla 3 Tratamiento antimicrobiano de la neumonía adquirida en la comunidad grave

Sin riesgo de Pseudomonas aeruginosa

Betalactámico $^{\mathrm{a}}+$ macrólido $^{\mathrm{b}}$

Betalactámico+quinolona antineumocócica ${ }^{c}$

Quinolona antineumocócica ${ }^{\mathrm{d}}+$ aztreonam $^{\mathrm{d}}$.

Riesgo de Pseudomonas aeruginosa

Betalactámico antipseudomonal ${ }^{\mathrm{e}}+$ quinolona

antipseudomonal $^{f}$

Betalactámico antipseudomonal+quinolona

antineumocócica + AG

Betalactámico antipseudomonal+macrólido+AG

Quinolona antineumocócica+aztreonam+AG

Quinolona antipseudomonal ${ }^{\mathrm{g}}+$ aztreonam $^{\mathrm{g}}$

${ }^{a}$ Ceftriaxona, cefotaxima.

${ }^{\mathrm{b}}$ Claritromicina, azitromicina.

'Levofloxacino $(750 \mathrm{mg})$.

${ }^{\mathrm{d}}$ Alergia a betalactámicos.

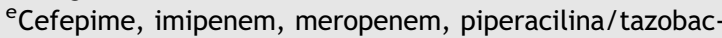
tam.

${ }^{f}$ Ciprofloxacino, levofloxacino $(750 \mathrm{mg})$.

${ }^{\text {g} A l e r g i a ~ a ~ b e t a l a c t a ́ m i c o s ; ~ A G: ~ a m i n o g l u c o ́ s i d o ~(g e n t a m i-~}$ cina, tobramicina, amikacina).

que se puede conseguir mediante una cefalosporina de tercera generación asociada a un macrólido o a una fluoroquinolona antineumocóccica ${ }^{2,5}$, tratamiento eficaz frente a la mayoría de los patógenos responsables de la NAC, incluyendo el neumococo resistente a la penicilina, siempre que la CMI para penicilina sea inferior a $4 \mu \mathrm{g} / \mathrm{ml} 0$ para cefotaxima a $2 \mu \mathrm{g} / \mathrm{ml}^{12}$ (tabla 3 ). Los pacientes con factores de riesgo de infección por Pseudomonas aeruginosa (fibrosis quística, EPOC grave, tratamiento crónico con esteroides), requieren tratamiento combinado frente a este patógeno, sin olvidar la cobertura frente a neumococo potencialmente resistente y Legionella $s p$ : cefepime, piperacilina-tazobactam, imipenem o meropenem asociados a una fluoroquinolona, o bien a un aminoglucósido y un macrólido ${ }^{2,5}$, ajustando el tratamiento cuando se dispone del resultado del cultivo, en función de su sensibilidad antibiótica. La NAC originada por $S$ aureus comunitario resistente a meticilina es una entidad poco frecuente que provoca cuadros de neumonía rápidamente progresiva en sujetos sanos, habitualmente tras una infección viral. Suele cursar como una neumonía necrotizante asociada a la producción de leucocidina de Panton-Valentine, así como a configuración genética, virulencia y patrón de susceptibilidad diferentes: sensibilidad constante a clindamicina, trimetoprim-sulfametoxazol y gentamicina, y variable a fluoroquinolonas ${ }^{13}$. El tratamiento óptimo no está claramente establecido: la vancomicina presenta una escasa penetración tisular y no reduce la producción de exotoxina, mientras que los efectos del trimetoprim-sulfametoxazol y de las fluoroquinolonas sobre la producción de toxinas no están claros. Así pues, el empleo de linezolid o bien la combinación de clindamicina y vancomicina, podrían ser los tratamientos adecuados $^{13}$.

La gripe afecta a todos los grupos de edad, con mayor mortalidad en los pacientes mayores de 65 años o con patología subyacente, habitualmente por neumonía bacteriana secundaria o bien, como es frecuente en la presente pandemia por gripe $\mathrm{A}(\mathrm{H} 1 \mathrm{~N} 1)$, por neumonía vírica primaria que provoca distrés respiratorio agudo y fracaso multiorgánico. Ante una NAC grave de etiología no filiada se debe considerar actualmente la investigación de la etiología vírica, y la posible administración de oseltamivir $(150 \mathrm{mg} /$ $12 \mathrm{~h}$ por vía oral, en forma de jarabe en pacientes intubados, durante 10 días).

En la NAC por aspiración se recomienda administrar amoxicilina+ácido clavulánico como tratamiento de elección, siendo una alternativa razonable la asociación de ertapenem y levofloxacino.

Los pacientes sépticos graves presentan incremento del volumen de distribución, que reduce los niveles séricos de los antibióticos que se distribuyen en el espacio extracelular (betalactámicos, aminoglucósidos, glicopéptidos). Asimismo, tras la infusión de líquidos y vasopresores los pacientes suelen presentar un índice cardíaco, aclaramiento de creatinina y eliminación de antibióticos hidrosolubles elevados. Por todo ello, en la NAC grave se debe emplear la máxima dosis recomendada, salvo si existen insuficiencias orgánicas.

Se ha consignado que el tratamiento combinado puede mejorar el pronóstico, especialmente en los pacientes más graves $^{14,15}$, explicado por la coinfección de neumococo con gérmenes atípicos, o también por el posible efecto sinérgico de un tratamiento combinado, aunque no existen datos que apoyen la citada sinergia entre betalactámicos y macrólidos, que es la combinación favorable más frecuente. Por el contrario, el beneficio mostrado en pacientes con shock aboga al efecto inmunomodulador de los macrólidos como el responsable de este beneficio.

Se preconiza la duración de la antibioterapia durante un mínimo de 5 días, hasta cumplirse 48-72 h tras la defervescencia de la fiebre. La gravedad del cuadro clínico, existencia de bacteriemia neumocóccica, complicaciones extrapulmonares o signos de necrosis requieren un tratamiento más prolongado.

Aunque no existe evidencia de que la vacuna neumocóccica reduzca el riesgo de neumonía, sí que reduce la mortalidad hospitalaria así como el riesgo de insuficiencia respiratoria en los pacientes que desarrollan $\mathrm{NAC}^{16}$.

\section{Meningitis}

La incidencia de la meningitis bacteriana comunitaria es de 1-3 casos por 100.000 habitantes. Streptococcus pneumoniae y Neisseria meningitidis son responsables del $80 \%$ de los casos. La asplenia (neumococo, meningococo), 
agammaglobulinemia (neumococo) y el déficit de las porciones finales del complemento (meningococo), son factores de riesgo para la infección. Listeria monocytogenes (4-8\%) afecta a mayores de 50 años, alcohólicos o jóvenes con inmunodeficiencia celular ${ }^{17}$. Las meningitis virales son causadas principalmente por enterovirus, con un pico de incidencia estacional a finales de verano y durante el otoño.

La sensibilidad de la triada clínica clásica, (fiebre, rigidez de nuca y alteración de la conciencia) es escasa (44\%). El 95\% presenta al menos 2 de estos 4 síntomas: fiebre, cefalea, rigidez de nuca y alteración del nivel de concien$\mathrm{cia}^{18}$. La focalidad neurológica (10-20\%), el papiledema y las convulsiones $(30 \%)$ obligan a la realización de una TAC craneal que descarte efecto masa, previa a la punción lumbar. La inmunodepresión severa y el GCS menor de 10 (14\%) indican también una TAC previa a la punción, que no debe retrasarse caso de no estar disponible la TAC ${ }^{19}$.

El análisis del líquido cefalorraquídeo (LCR) es la base del diagnóstico. En las meningitis bacterianas se objetiva pleocitosis $\left(1.000-5.000\right.$ células $\left./ \mathrm{mm}^{3}\right)$ de predominio polimorfonuclear (80-95\%), siendo frecuente la hipoglucorraquia ( $<40 \mathrm{mg} / \mathrm{dl})$, acompañada de la presencia de cociente glucosa en LCR/glucemia $\leq 0,4$, con una alta sensibilidad $y$ especificidad. Las meningitis víricas presentan pleocitosis moderada $\left(10-500\right.$ células $\left./ \mathrm{mm}^{3}\right)$, con predominio de linfocitos y sin consumo de glucosa. Se aprecia hiperproteinorraquia (proteínas $>50 \mathrm{mg} / \mathrm{dl}$ ) en todos los pacientes con meningitis.

La tinción de Gram permite una rápida identificación en el 60-90\% de los casos (especificidad del 97\%), recomendándose su realización urgente en toda sospecha de meningitis ${ }^{20}$. Su sensibilidad se reduce drásticamente en pacientes bajo antibioterapia. Las técnicas de detección de antígenos cobran valor en los casos con tratamiento antimicrobiano previo cuya tinción de Gram resulta negativa ${ }^{20}$.

Las técnicas de amplificación de ADN (PCR) de amplio espectro a tiempo real son útiles por su rapidez, sensibilidad y especificidad para excluir la meningitis bacteriana ${ }^{21}$, cobrando relevancia en los casos con antibioterapia previa y/o tinción de Gram negativa. En los pacientes inmunocompetentes con sospecha de meningitis vírica debe practicarse una PCR para herpes virus, virus varicela-zoster y enterovirus.

La medición de proteína $C$ reactiva sérica en pacientes con tinción de Gram negativa tiene un alto valor predictivo negativo. La procalcitonina resulta útil para diferenciar entre las meningitis bacterianas y víricas, con un punto de corte situado en $0,2 \mathrm{ng} / \mathrm{ml}$. Su rápida normalización ante la antibioterapia adecuada permite monitorizar la efectividad del tratamiento ${ }^{18}$. La medición del lactato en LCR no se recomienda de rutina ${ }^{20}$. Los hemocultivos, (positivos en el $50 \%$ ), resultan de gran relevancia en pacientes con tinción de Gram no identificativa $(70 \%$ de meningitis por $L$. monocytogenes).

El retraso en el tratamiento de las meningitis aumenta la morbimortalidad, justificando la administración precoz y empírica de cefalosporinas de tercera generación asociadas a vancomicina, [cobertura de $S$. pneumoniae resistente a penicilinas $(18 \%)$ y cefalosporinas $(9 \%)$. Si se considera L.monocytogenes debe añadirse ampicilina. Tras identificar el germen se debe modificar el tratamiento según antibiograma y penetración en LCR, siendo aconsejable el uso de antimicrobianos bactericidas ${ }^{17,18}$ (tabla 4). La vancomicina debe asociarse a cefalosporinas de tercera generación, aún en las cepas resistentes ${ }^{20}$. El tratamiento debe comenzar inmediatamente después de la punción lumbar, o sin esperar a la realización de la misma si se requiere TAC previa (fig. 1).

Los corticoides deben administrarse previos o simultáneos al inicio de la antibioterapia empírica en toda sospecha de meningitis bacteriana, independientemente de su etiología específica $^{22}$. Los corticoides no disminuyen habitualmente los niveles de vancomicina en LCR, si la dosis usada es apropiada $^{23}$. En situación de shock séptico se aconseja priorizar la administración de dosis «fisiológicas» de corticoides $^{19}$. La proteína $C$ activada, aunque no aumenta el riesgo global de sangrado grave, se relaciona con un discreto aumento de la hemorragia intracraneal en las meningitis, que requiere realizar estudios específicos para su correcta evaluación, por lo que su uso debe individualizarse ${ }^{24,25}$.

Tabla 4 Modificado de Ziai WC

Tratamiento específico de la meningitis bacteriana en adultos.

\begin{tabular}{|c|c|c|c|}
\hline Germen & Resistencias & Antibioterapia & Duración \\
\hline S. penumoniae & $\begin{array}{l}\text { Penicilina CMI }<0,1 \mu \mathrm{g} / \mathrm{ml} \\
\quad 0,1-1 \mu \mathrm{g} / \mathrm{ml} \\
>2 \mu \mathrm{g} / \mathrm{ml} \\
\text { Ceftriaxona } \mathrm{CMI}>0,1\end{array}$ & $\begin{array}{l}\text { Penicilina } G \text { o ampicilina. } \\
\text { Cefalosporina } 3 .^{\mathrm{a}} \text { generación. } \\
\text { Vancomic+Cefalosporina } 3^{\mathrm{a}} \\
\text { Vancomic+Cefalosporina } 3^{\mathrm{a}}\end{array}$ & 10-14 días \\
\hline N.meningitides & & Penicilina $\mathrm{G}$ o ampicilina o Cefalosporina $3^{\mathrm{a}}$ & 7-10 días \\
\hline H.influenzae & & Cefalosporina $3^{\mathrm{a}}$ & 7-10 días \\
\hline L.monocytogenes & & Ampicilina \pm gentamicina & 21 días \\
\hline Streptococcus grupo B & & Penicilina $\mathrm{G}$ o ampicilina. & 14-21 días \\
\hline Enterobacteriaceae & & Cefalosporina $3 .^{a} \pm$ gentamicina o ciprofloxacino & 14-21 días \\
\hline P. aeruginosa & & Cefepime o cefatzidima \pm gentamicina o ciprofloxacino & 14-21 días \\
\hline \multirow{2}{*}{ S. aureus } & Meticilín sensible & Cloxacilina & \\
\hline & Meticilín resistente & Vancomicina \pm rifampicina & 14-21 días \\
\hline S.epidermidis & Meticilín resistente & Vancomicina \pm rifampicina & 14-21 días \\
\hline
\end{tabular}

Update in the diagnosis and management of central nervous system infections. Neurol Clin 2008. 


\section{Sospecha de meningitis}
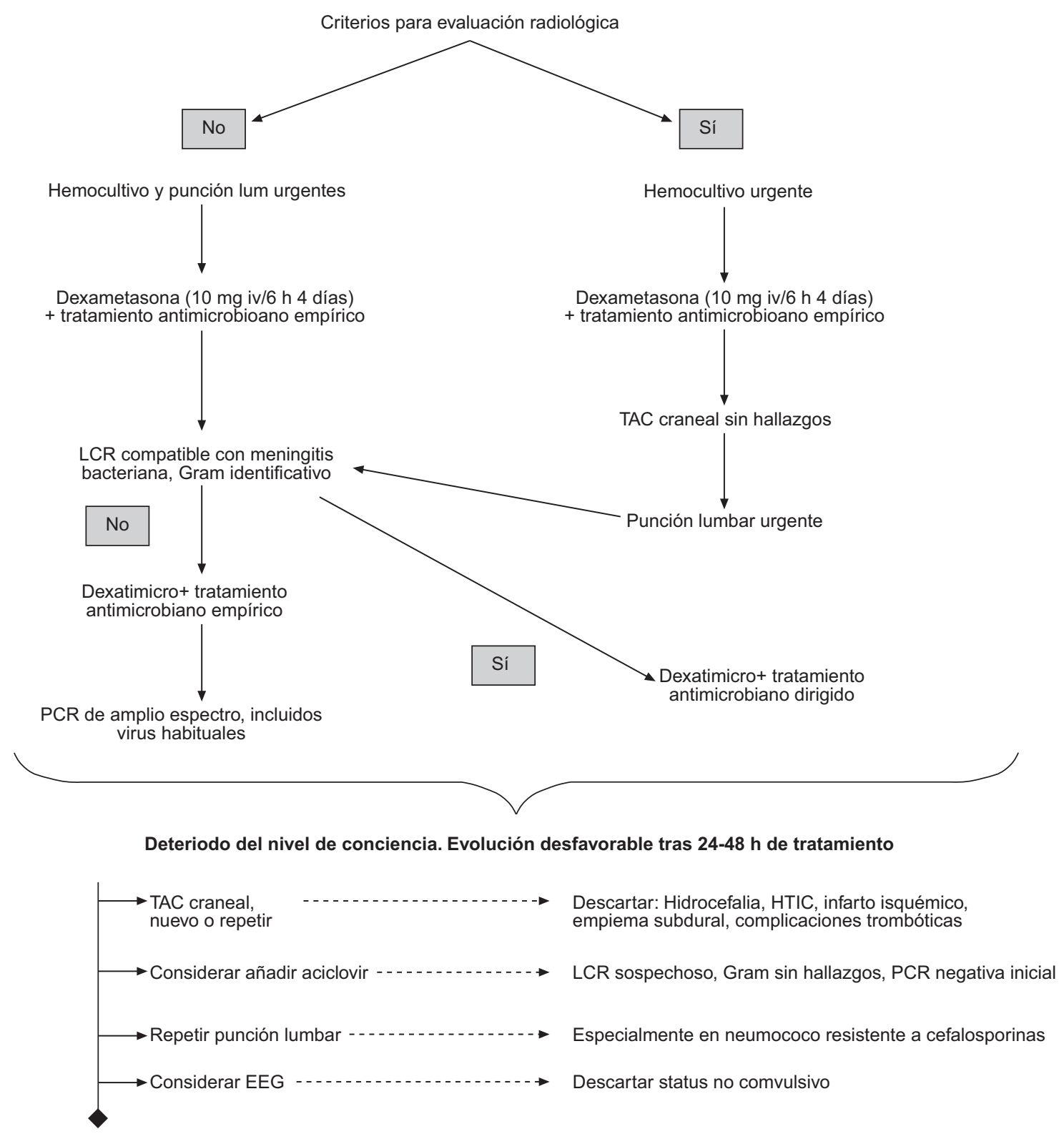

Figura 1 Algoritmo de actuación frente a sospecha de meningitis. Modificado de Tunkel AR, et al. Practice guidelines for the management of bacterial meningitis. Clin Infect Dis 2004.

La afectación cerebral (meningoencefalitis) causa frecuentemente deterioro progresivo del nivel de conciencia, así como crisis epilépticas; sin embargo, la profilaxis anticomicial no está indicada, aunque sí el tratamiento enérgico de las crisis. El edema vasogénico, que conlleva hipertensión intracraneal (HTIC) grave (signos clínicos, radiológicos o sonográficos), afecta al nivel de conciencia, debiendo valorarse la monitorización invasiva de la presión intracraneal y su tratamiento si procede ${ }^{26,27}$. La hidrocefalia, aunque infrecuente, puede provocar deterioro. Su tratamiento (punción lumbar repetida, drenaje permanente, ventriculostomía), dependerá de la valoración clínica y radiológica. La hiponatremia moderada es habitual, pudiendo ser secundaria a una secreción inadecuada de $\mathrm{ADH}$. En los casos de hipertensión intracraneal grave debe ser corregida.

\section{Encefalitis}

La etiología mayoritaria de las encefalitis es desconocida (32-75\%), siendo los virus los gérmenes más involucrados (Herpes simple tipo 1, virus del Nilo occidental, enterovirus).

El análisis del LCR, crucial para el diagnóstico, muestra una pleocitosis mononuclear moderada, aunque en fases iniciales puede detectarse un aumento de neutrófilos. Existe 
hiperproteinorraquia moderada sin consumo de glucosa, aunque un $10 \%$ cursa sin alteraciones en LCR. La detección de anticuerpos IgM frente a virus en LCR se considera diagnóstica, dado que no cruzan la barrera hematoencefálica. Las determinaciones etiológicas por PCR en LCR son la base del diagnóstico, especialmente en el caso del herpes virus, donde alcanza una sensibilidad y especificidad precoces que son superiores al 95\%, permaneciendo la positividad durante la primera semana de tratamiento. Ante un primer resultado negativo se aconseja una segunda determinación tras 3 días de tratamiento. El virus varicelazoster (VVZ), Ebstein-Barr (VEB) y citomegalovirus (CMV), son susceptibles de diagnóstico mediante PCR.

La neuroimagen es el segundo pilar del estudio etiológico, siendo la RM la técnica de elección, más sensible y específica que la TAC. El edema y la hemorragia afectando el lóbulo temporal son muy sugestivos de encefalitis por herpes simple, siendo prácticamente patognomónica si es bilateral.

La terapéutica específica en la encefalitis viral se reduce al tratamiento con aciclovir para los herpes virus, cuyo retraso se ha asociado con resultados negativos, recomendándose su inicio precoz ante sospecha de meningitis/ encefalitis vírica y en espera de los estudios analíticos ${ }^{28}$. Tras 14-21 días sin respuesta clínica positiva se recomienda nueva PCR, prolongando el tratamiento en caso de ser positivo. El VVZ puede tratarse con aciclovir, mientras que para CMV se ha usado ganciclovir y foscarnet.

\section{Infección urinaria}

Es la infección nosocomial más frecuente en salas de hospitalización, mientras que en las UMI ocupan el segundo lugar, tras las neumonías asociadas a ventilación mecáni$\mathrm{ca}^{29}$. Originan el $5-7 \%$ de las sepsis graves que precisan ingreso en $\mathrm{UCI}$, donde no es infrecuente encontrar casos de infección urinaria que desarrollan sepsis grave, con evolución rápida a fallo multiorgánico en pacientes previamente $\operatorname{sanos}^{30,31}$. Es la causa más frecuente de bacteriemia de origen comunitario, por encima de las neumonías.

Con respecto a la patogenia, los gérmenes que colonizan la uretra anterior o el introito vaginal, ascienden hasta la vejiga. La diseminación hematógena desde otros focos ocurre solo ocasionalmente, siendo el germen implicado con mayor frecuencia el $S$. aureus, y ocasionalmente Cándida.

Se considera que existen factores genéticos que parecen condicionar una mayor facilidad para que $E$. coli se adhiera a las células epiteliales en algunas mujeres que padecen infecciones frecuentes del tracto urinario (ITU). Todos los pacientes con sonda permanente desarrollarán bacteriuria. La colonización se produce tanto endoluminalmente, con formación de biocapa (similar a la que conocemos en los catéteres venosos), como en la zona extraluminal.

Las cepas bacterianas que producen ITU en pacientes previamente sanos requieren unos factores de virulencia específicos para provocar estos cuadros, que además suelen afectar al parénquima renal y pueden ser extraordinariamente graves. Las cepas implicadas en las infecciones que desarrollan los pacientes con alteraciones funcionales 0 estructurales del sistema excretor, no exhiben necesariamente dichos factores, que incluyen: a) «Pili» o fimbrias, que median la adherencia a células de vagina y urotelio; b) resistencia a los factores bactericidas del suero; c) producción de hemolisinas; d) presencia de aerobactina cromosómica o una mayor cantidad de antígeno capsular $\mathrm{K}$ del $E$. coli. La adhesión está mediada por ligandos bacterianos específicos a los receptores carbohidratos de la pared celular del huésped.

La protección más importante del huésped se debe a la producción y eliminación de orina, que diluye y elimina el inóculo. La orina residual vesical, debida a alteraciones funcionales o estructurales en la eliminación, aumenta en gran medida las posibilidades de infección. El pH ácido, la concentración de urea y la osmolalidad extrema de la orina, son un ambiente hostil para el crecimiento de microorganismos anaerobios y otros muchos gérmenes. La producción de la proteína Tamm-Horsfall en las células epiteliales renales supone una barrera para la infección, al tener un alto contenido en manosa, que liga las adhesinas de las enterobacterias competitivamente y dificulta por lo tanto su adhesión al epitelio.

Las ITU se clasifican según el síndrome clínico en infecciones del tracto urinario inferior (cistitis) o superior.

1. Cistitis. Es la situación más frecuente en las infecciones comunitarias. Se acompaña de disuria, polaquiuria, tenesmo y dolor suprapúbico. Producen rara vez bacteriemia, siendo muy poco frecuente su ingreso en UMI. Una entidad especial, la cistitis enfisematosa ${ }^{32}$, puede condicionar un cuadro clínico más grave, que cursa incluso con shock séptico fulminante. Se diagnostica por técnicas de imagen, y en ocasiones una simple Rx de abdomen muestra gas en la pared vesical. Los microorganismos más frecuentemente involucrados son $E$ coli y Klebsiella; es rara la infección por gérmenes anaerobios.

2. Urosepsis altas. Son más graves, suelen darse en pacientes más jóvenes y evolucionan en ocasiones de manera fulminante a shock séptico, con una mortalidad estimada cercana al 30\%. La más importante es la pielonefritis obstructiva aguda, provocada en el $98 \%$ de los casos por litiasis. Cursa a veces de manera asintomática y no se aprecia dilatación inicial de la vía urinaria. Evoluciona con dolor lumbar y en flanco, tumefacción de las fosa renal, íleo y peritonismo. La ecografía y el TAC

Tabla 5 Comparación de aislamientos en ITU de la comunidad y en la UCI

\begin{tabular}{|c|c|c|}
\hline Microorganismos & Comunidad (\%) E & Envin - UCI (\%) \\
\hline Escherichia coli & 73 & 26 \\
\hline Klebsiella pneumoniae & 5,4 & 4,8 \\
\hline Proteus mirabilis & 7,2 & 5,5 \\
\hline Proteus spp. & 1 & 0,2 \\
\hline Pseudomonas aeruginosa & 1,3 & 7 \\
\hline Klebsiella spp. & 1,2 & 0,4 \\
\hline Enterobacter spp. & 0,9 & 1,6 \\
\hline Otros bacilos gramnegativos & 1,7 & 4 \\
\hline Enterococcus spp. & 4,8 & 24,8 \\
\hline Estreptococcus agalactiae & 1,7 & 0,4 \\
\hline Otros grampositivos & 1,8 & 4,3 \\
\hline Candida spp. & - & 21 \\
\hline
\end{tabular}


Tabla 6 Tratamiento empírico de las ITU

\begin{tabular}{|c|c|c|c|c|c|}
\hline \multicolumn{2}{|l|}{ Situación clínica } & \multirow[t]{2}{*}{ Circunstancias específicas } & \multirow[t]{2}{*}{ Etiologías más frecuentes } & \multicolumn{2}{|l|}{ Tratamiento indicado } \\
\hline Sitio & Diagnóstico & & & De elección & Alternativo \\
\hline \multirow{7}{*}{$\begin{array}{l}\text { Riñón y vías } \\
\text { urinarias } \\
\text { (Infecciones del } \\
\text { tracto urinario, } \\
\text { ITU) }\end{array}$} & \multirow[t]{4}{*}{$\begin{array}{l}\text { Cistitis aguda no } \\
\text { complicada, en mujeres }\end{array}$} & En general & $\begin{array}{l}\text { E. coli }(80 \%) \text { Klebsiella spp., } \\
\text { Proteus mirabilis, etc. }\end{array}$ & $\begin{array}{l}\text { Fosfomicina-trometamol } \\
\text { ( } 3 \mathrm{~g} \text { oral en dosis umca) }\end{array}$ & $\begin{array}{l}\text { Ciprofloxacino }(500 \mathrm{mg} / \\
12 \mathrm{~h} \text { oral, } 3 \text { días) }\end{array}$ \\
\hline & & $\begin{array}{l}\text { Si }>65 \text { años, diabetes, } \\
\text { síntomas }>7 \text { días o ITU } \\
\text { reciente }\end{array}$ & & $\begin{array}{l}\text { Amoxicilina-clavulanico } \\
875 / 125 \mathrm{mg} / 8 \mathrm{~h} \text { oral, } \\
10 \text { días }\end{array}$ & $\begin{array}{l}\text { Ciprofloxacino ( } 500 \mathrm{mg} / \\
12 \mathrm{~h} \text { oral, } 10 \text { días) }\end{array}$ \\
\hline & & $\begin{array}{l}\text { Gestante (la piuria } \\
\text { asintomática es criterio de } \\
\text { tratamiento antibiótico en } \\
\text { gestantes) }\end{array}$ & & $\begin{array}{l}\text { Fosfomicina-trometamol } \\
\text { ( } 3 \mathrm{~g} / 48 \mathrm{~h} \text { oral, } 3 \text { dosis) }\end{array}$ & $\begin{array}{l}\text { Amoxicilina-clavulánico } \\
\text { (875/125 mg/8 h oral, } 10 \\
\text { días) }\end{array}$ \\
\hline & & $\begin{array}{l}\text { Si además existe sospecha } \\
\text { de ETS }\end{array}$ & $\begin{array}{l}\text { Además: Chlamydia } \\
\text { trachomatis }\end{array}$ & $\begin{array}{l}\text { Asociar: Doxiciclina } \\
\text { (100 mg/12 h oral) }\end{array}$ & \\
\hline & \multirow[t]{2}{*}{$\begin{array}{l}\text { Pielonefritis aguda no } \\
\text { complicada, en mujeres }\end{array}$} & $\begin{array}{l}\text { Leve o moderada, no } \\
\text { sospecha de sepsis } \\
\text { (tratameinto ambulatorio) }\end{array}$ & $\begin{array}{l}\text { E. coli, Proteus mirabilis, } \\
\text { Klebsiella pneumoniae, S. } \\
\text { saprophyticus }\end{array}$ & $\begin{array}{l}\text { Amoxicilina-clavulánico } \\
\text { ( } 875 / 125 \mathrm{mg} / 8 \mathrm{~h} \text { oral, } \\
10 \text { días) }\end{array}$ & $\begin{array}{l}\text { Ciprofloxacino }(500 \mathrm{mg} / \\
12 \mathrm{~h} \text { oral) o Ceftibuteno } \\
\text { ( } 400 \mathrm{mg} / 24 \mathrm{~h} \text { oral), } 10 \\
\text { dias }^{7}\end{array}$ \\
\hline & & $\begin{array}{l}\text { Afección importante, } \\
\text { sospecha de sepsis o en } \\
\text { gestante (tratamiento } \\
\text { hospitalario) }\end{array}$ & & $\begin{array}{l}\text { Ceftriaxona }(1-2 \mathrm{~g} / 24 \mathrm{~h} \text { IV) o } \\
\text { Cefotaxima }(1-2 \mathrm{~g} / 8 \mathrm{~h} \mathrm{IV}) \text { o } \\
\text { Tobramicina }(5 \mathrm{mg} / \mathrm{Kg} / 24 \mathrm{~h} \text {, } \\
\text { IV) Si riesgo } \mathrm{BLEE}^{2} \text { : } \\
\text { Ertapenem } 1 \mathrm{~g} / 24 \mathrm{~h} \text { IV }\end{array}$ & $\begin{array}{l}\text { Ciprofloxacino ( } 400 \mathrm{mg} / \\
12 \mathrm{~h} \mathrm{IV)} \mathrm{(excepto} \mathrm{en} \\
\text { gestante) }\end{array}$ \\
\hline & $\begin{array}{l}\text { ITU complicada } \\
\text { (presencia de } \\
\text { obstrucción, reflujo, } \\
\text { insuficiencia renal } \\
\text { crónica, } \\
\text { transplantados, etc.) }\end{array}$ & $\begin{array}{l}\text { Salvo excepciones, } \\
\text { considerer siempre } \\
\text { tratamiento hospitalario }\end{array}$ & $\begin{array}{l}\text { E. coli, Proteus spp., } \\
\text { Klebsiella spp., } \\
\text { Pseudomonas spp. Serratia } \\
\text { spp., enterococo, } \\
\text { estafilococos }\end{array}$ & $\begin{array}{l}\text { Ceftriaxona }(1-2 \mathrm{~g} / 24 \mathrm{~h} \text { IV) o } \\
\text { Cefotaxima }(1-2 \mathrm{~g} / 8 \mathrm{~h} \mathrm{IV}) \text { o } \\
\text { Tobramicina }(5 \mathrm{mg} / \mathrm{KG} / 24 \mathrm{~h} \\
\text { IV) (excepto en insuficiencia } \\
\text { renal) o Cefepima }(2 \mathrm{~g} / 12 \mathrm{~h} \\
\text { IV) Si riesgo BLEE: } \\
\text { Imipenem } 2 \mathrm{a} 1 \mathrm{~g} / 8 \mathrm{~h} \mathrm{IV}\end{array}$ & $\begin{array}{l}\text { Ciprofloxacino }(400 \mathrm{mg} / \\
12 \mathrm{~h} \mathrm{IV}) \text { (excepto en } \\
\text { gestante) o Imipenem } \\
(1 \mathrm{~g} / 8 \mathrm{~h} \mathrm{IV})\end{array}$ \\
\hline
\end{tabular}


son medios diagnósticos útiles. Una tinción de Gram de la orina puede orientarnos rápidamente hacia el agente etiológico. En los casos con progresión a sepsis grave y shock séptico, se produce bacteriemia hasta en el $70 \%$ de los $\operatorname{casos}^{33}$.

La mortalidad por ITU se considera escasa, ya que suele responder rápidamente al tratamiento; es uno de los focos en los que se debe pensar cuando no hay causa evidente en un paciente séptico, especialmente en ancianos. En todos los casos sospechosos de ITU, se debería estudiar el sedimento y realizar tinción de Gram (aunque este estudio aporta un mayor beneficio en la ITU nosocomial, donde la microbiota responsable es más variada).

Los microorganismos responsables más frecuentes son similares en las distintas series (tabla 5). Se aprecia una diferencia sustancial respecto a las ITU nosocomiales que se producen en la $\mathrm{UCl}$ asociadas al sondaje urinario, donde se aprecia con respecto a las ITU comunitarias un menor peso de $E$. coli, el frecuente aislamiento de Candida y el mayor porcentaje de otros gérmenes potencialmente resistentes a antibióticos como Pseudomonas, enterococos $\mathrm{y}$ otros microorganismos gram positivos como estafilococos ${ }^{34}$.

Un estudio reciente incluyó 122 casos de infecciones comunitarias por bacterias productoras de betalactamasa de espectro extendido (BLEE), de las que el 92\% eran ITU. Los factores de riesgo que definió el análisis multivariante incluyeron la edad superior a 60 años, sexo femenino, DM, ITU previas recurrentes, antecedentes de procedimiento invasor, seguimiento clínicoambulatorio y tratamiento previo con aminopenicilinas, cefalosporinas y fluorquinolonas ${ }^{35}$.

Las bacterias productoras de BLEE eran raras en España hasta el año 1996, pero han ido aumentando progresivamente, hasta alcanzar en algún hospital cifras que llegan a $16,7 \%$ en aislamientos de $K$. pneumoniae, siendo las áreas con mayor prevalencia Madrid, Cataluña, Valencia y Andalucía (7-13\%). También se están detectando en cepas de $E$. coli procedentes de muestras de orina y en heces de portadores sanos, hasta el 7,5\%; cabe suponer que la extensión de las BLEE es generalizada. En un análisis retrospectivo de 5.247 aislamientos de E.coli procedentes de urinocultivos se muestra una tendencia creciente en cuanto a los aislamientos de productores de BLEE durante el período estudiado (2000-2005). Su incidencia fue del 0,8\% en 2000-2001, el 2,5\% en 2001-2002 y también en 2002-2003, y el 3,5\% en 2004-2005 ${ }^{36}$.

Especialmente en la ITU graves, se suele iniciar el tratamiento de modo empírico. El $90 \%$ de los gérmenes que se aíslan en infecciones comunitarias son bacilos gramnegativos, que llegan al $95 \%$ en casos graves. Dentro de los grampositivos, son los enterococos los gérmenes aislados con mayor frecuencia, aunque rara vez provocan infecciones que requieran ingreso en $\mathrm{UCl}$. El esquema de tratamiento se propone en la tabla 6.

Ante pacientes que presentan factores de riesgo para bacterias productoras de BLEE, se usarán carbapenemes de entrada, especialmente si tienen infección urinaria adquirida en el hospital que requiere ingreso en $\mathrm{UCl}$. Algunos antibióticos, por la alta concentración que alcanzan en orina (especialmente las cefalosporinas), podrían usarse con seguridad en ITUs bajas, incluso graves. En pielonefritis deben usarse carbapenemes, o bien tigeciclina en caso de alergia o intolerancia a dichos antibióticos.

\section{Bibliografía}

1. Donowitz G, Mandell G. Acute pneumonia. En: Mandell G, Bennett J, Dolin R, editores. Principles and Practice of infectious Diseases. Philadelphia: Elsevier Churchill Livingstone; 2005. p. 819-45.

2. Alvarez-Rocha A, Alós JI, Blanquer J, Alvarez-Lerma F, Garau J, Guerrero A, et al. Guías para el manejo de la neumonía comunitaria del adulto que precisa ingreso en el hospital. Med Intensiva. 2005;29:21-62.

3. Bodí M, Rodríguez A, Solé-Violán J, Gilavert MC, Garnacho J, Blanquer J, et al. Antibiotic prescription for communityacquired pneumonia in the intensive care unit: impact of adherence to Infectious Diseases Society of America guidelines on survival. Clin Infect Dis. 2005;41:1709-16.

4. Marcos MA, Esperatti M, Torres A. Viral pneumonia. Curr Opin Infect Dis. 2009;22:143-7.

5. Mandell LA, Wunderink RG, Anzueto A, Bartlett JG, Campbell GD, Dean NC, et al. Infectious Diseases Society of America/American Thoracic Society consensus guidelines on the management of community-acquired pneumonia in adults. Clin Infect Dis. 2007;44:S27-72.

6. Charles PG, Wolfe R, Whitby M, Fine MJ, Fuller AJ, Stirling R, et al. SMART-COP: a tool for predicting the need for intensive respiratory or vasopressor support in community-acquired pneumonia. Clin Infect Dis. 2008;47:375-84.

7. Renaud B, Labarère J, Coma E, Santin A, Hayon J, Gurgui M, et al. Risk stratification of early admission to the intensive care unit of patients with no major criteria of severe communityacquired pneumonia: development of an international prediction rule. Crit Care. 2009;13:R54.

8. Menéndez R, Martínez R, Reyes S, Mensa J, Filella X, Marcos MA, et al. Biomarkers improve mortality prediction by prognostic scales in community-acquired pneumonia. Thorax. 2009;64: 587-91.

9. Rello J, Rodríguez A, Lisboa T, Gallego M, Luján M, Wunderink R. PIRO score for community-acquired pneumonia: a new prediction rule for assessment of severity in intensive care unit patients with community-acquired pneumonia. Crit Care Med. 2009;37:456-62.

10. Blot SI, Rodríguez A, Solé-Vlolán J, Blanquer J, Almirall J, Rello J. Effects of delayed oxygenation assessment on time to antibiotic delivery and mortality in patients with severe communityacquired pneumonia. Crit Care Med. 2007;35:2509-14.

11. Brito V, Niederman MS. Healthcare-associated pneumonia is a heterogeneous disease, and all patients do not need the same broad-spectrum antibiotic therapy as complex nosocomial pneumonia. Curr Opin Infect Dis. 2009;22:316-25.

12. Lynch 3rd JP, Zhanel GG. Streptococcus pneumoniae: does antimicrobial resistance matter? Semin Respir Crit Care Med. 2009;30:210-38.

13. Bassetti M, Nicco E, Mikulska M. Why is community-associated MRSA spreadind across the world and how will it change clinical practice? Int J Antimicrob Agents. 2009;34:S15-9.

14. Rodríguez A, Mendía A, Sirvent JM, Barcenilla F, de la TorrePrados MV, Solé-Violán J, et al. Combination antibiotic therapy improves survival in patients with community-acquired pneumonia and shock. Crit Care Med. 2007;35:1493-8.

15. Olaechea P. Infecciones bacterianas en el paciente crítico: revisión de los estudios publicados entre 2006 y 2008 . Med Intensiva. 2009;33:196-206.

16. Ochoa-Gondar O, Vila-Córcoles A, Ansa X, Rodríguez-Blanco T, Salsench E, de Diego $C$, et al. Effectiveness of pneumococcal 
vaccination in older adults with chronic respiratory diseases: results of the EVAN-65 study. Vaccine. 2008;26:1955-62.

17. Honda $\mathrm{H}$, Warren DK. Central nervous system infections: meningitis and brain abscess. Infect Dis Clin North Am. 2009;23:609-23.

18. Ziai WC, Lewin III JJ. Update in the diagnosis and management of central nervous system infections. Neurol Clin. 2008;26: 427-68.

19. van de Beek D, de Gans J, Tunkel AR, Widjdicks EF. Communityacquired bacterial meningitis in adults. N Engl J Med. 2006;354: 44-53.

20. Tunkel AR, Hartman BJ, Kaplan SL, Kaufman BA, Roos KL, Scheld WM, et al. Practice guidelines for the management of bacterial meningitis. Clin Infect Dis. 2004;39:1267-84.

21. Deutch S, Pedersen LN, Podenphant L, Olesen R, Schmidt MB, Moller JK, et al. Broad-range real time PCR and DNA sequencing for the diagnosis of bacterial meningitis. Scand J Infect Dis. 2006;38:27-35.

22. Van de Beek D, de Gans J, Mc Intyre P, Prasad K. Corticosteroids for acute bacterial meningitis. Cochrane Database Syst Rev. 2007:CD004405.

23. Ricard JD, Wolff M, Lacherade JC, Mourvillier B, Hidri N, Barnaud $G$, et al. Levels of vancomycin in cerebrospinal fluid of adults patients receiving adjunctive corticosteroids to treat pneumococcal meningitis: a prospective multicenter observational study. Clin Infect Dis. 2007;44:250-5.

24. Camporota L, Wyncoll D. Practical aspects of treatment with drotrecogin alfa (activated). Crit Care. 2007;11(Suppl 5):S7.

25. Vincent JL, Nadel S, Kutsogiannis DJ, Gibney RT, Yan SB, Wyss VL, et al. Drotrecogin alfa (activated) in patients with severe sepsis presenting with purpura fulminans, meningitis, or meningococcal disease: a retrospective analysis of patients enrolled in recent clinical studies. Crit Care. 2005;9:R331-43.

26. Lindvall P, Ahlm C, Ericsson M, Gothefors L, Naredi S, Koskinen LO. Reducing intracranial pressure may increase survival among patients with bacterial meningitis. Clin Infect Dis. 2004;38:384-90.

27. Grande PO, Myhre EB, Nordstrom CH, Schliamser S. Treatment of intracranial hypertension and aspects on lumbar dural puncture in severe bacterial meningitis. Acta Anaesthesiol Scand. 2002;46:264-70.

28. Tunkel AR, Glaser CA, Bloch KC, Sejvar JJ, Marra CM, Roos KL, et al. The management of encephalitis: clinical practice guidelines by the Infectious Diseases Society of America. Clin Infect Dis. 2008;47:303-27.

29. Grupo de Trabajo de Enfermedades Infecciosas de la Sociedad Española de Medicina Intensiva Crítica y Unidades Coronarias. Estudio Nacional de Vigilancia de Infección Nosocomial en Servicios de Medicina Intensiva (ENVIN). Informe anual 2008.

30. Blanco J, Muriel-Bombín A, Sagredo V, Taboada F, Gandía F, Tamayo L, et al. Grupo de Estudios y Análisis en Cuidados Intensivos. Incidence, organ dysfunction and mortality in severe sepsis: a Spanish multicentre study. Crit Care. 2008;12:R158.

31. Laupland KB, Baghaw SM, Gregson DB, Kirkpatrick AW, Ross T, Church DL. Intensive care unti acquired urinary tract infections in a regional critical care system. Crit Care. 2005;9: R60-5.

32. Sánchez Pulgarín I, Kessler Saiz P, Odriozola Grijalva M. Cistitis Enfisematosa. An Med Interna. 2006;23:602-3.

33. Terradas $\mathrm{R}$, Grau $\mathrm{S}$, Knobel $\mathrm{H}$, Álvarez-Lerma $\mathrm{F}$, Riu $\mathrm{M}$, Salvadó M. Bacteriemia comunitaria tratada o identificada de forma ambulatoria tras el alta de un Servicio de Urgencias. Med Clin (Barc). 2007;129:652-4.

34. Andreu A, Alós JI, Gobernado M, Marco F, Rosa M, GarcíaRodríguez JA, Grupo Cooperativo Español para el Estudio de la Sensibilidad Antimicrobiana de los Patógenos Urinarios. Etiología y sensibilidad a los antimicrobianos de los uropatógenos causantes de la infección urinaria baja adquirida en la comunidad. Estudio nacional multicéntrico. Enferm Infecc Microbiol Clin. 2005;23(1):4-9.

35. Rodríguez-Baño J, Alcalá J, Cisneros J, Grill F, Oliver A, Horcajada J, et al. Community infections caused by extendedspectrum $\beta$-lactamase-producing Escherichia coli. Arch Intern Med. 2008;168:1897-902.

36. Caro M, Hernando S, Carrero P, García S. Estudio de multirresistencia antibiótica de Escherichia coli en urocultivos. Med Clin (Barc). 2007;129:409-11. 